\title{
Advanced Integrated Modeling and Measurement: The Global Carbon Cycle
}

\author{
P B Duffy \\ J Amthor \\ K. Caldeira \\ J Chambers \\ J Dignon \\ J Kercher \\ G. Rau \\ J Southon
}

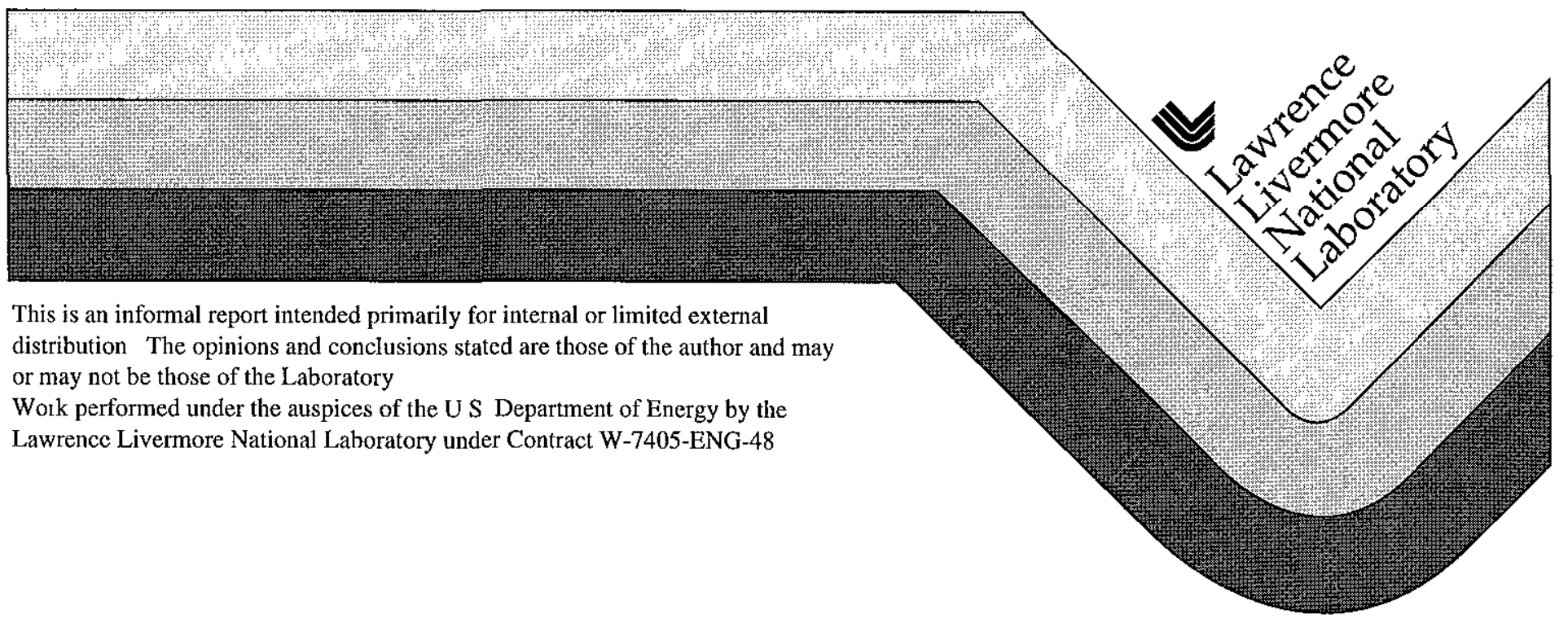




\section{DISCLAIMER}

This document was prepared as an account of work sponsored by an agency of the Linited States Government Neither the United States Government nor the University of California nor any of their employees, makes any warranty, express or implied, or assumes any legal liability or responsibility for the accuracy, completeness, or usefulness of any irformation, apparatus, product, or process disclosed, or represents that its use would not infringe privately owned rights Reference herein to any specific commercial product, process, or service by trade name, trademark, manufacturer, or otherwise, does not necessarily constitute or imply its endorsement, recommendation, or favoring by the United States Goverrment or the University of California The views and opinions of authors expressed herein do not necessarily state or reflect those of the United States Government or the University of California, and shall not be used for advertising or product endorsement purposes

This report has been reproduced directly from the best available copy

Available to DOE and DOE contractors from the Office of Scientific and Technical Information

PO Box 62, Oak Ridge, TN 37831

Prices av ailable from (423) 576-8401

Available to the public from the National Technical Information Service

US Department of Commerce 5285 Port Royal Rd. Springfield, VA 22161 
LDRD Strategic Initiative Final Report

Advanced Integrated Modeling and Measurement The Global Carbon Cycle

Philip B Duffy

Jeff Amthor, Ken Caldeira, Jeff Chambers, Jane Dignon,

Jim Kercher, Greg Rau and John Southon

95-DI-005

\section{Introduction}

Most of the carbon dioxide added to the atmosphere by human activities comes from burning fossil fuels Only about half the $\mathrm{CO}_{2}$ we telease into the atmosphere remains there, however, and the fate of the $\mathrm{CO}_{2}$ that does not remain in the atmosphere is uncertain As carbon dioxide comes in contact with the sea surface it may be absorbed into the ocean, and as it comes in contact with the leaves of plants it may be absorbed and transformed into plant tissue, but the rates at which the sea or land plants can absorb $\mathrm{CO}_{2}$ ate pootly characterized Hence, there is a great deal of uncertainty as to how much of the $\mathrm{CO}_{2}$ we release today will be found in the ocean, or in land plants, or in the atmosphete 10,20 or 100 years from now The nartowing of these uncertainties is essential to making reliable predictions of the climate consequences of fossil fuel burning and deforestation

To narrow these uncertainties, we have developed one of the most sophisticated carbon cycle models in the world This model considers transport of $\mathrm{CO}_{2}$ in the atmosphere, the consumption and respiration of $\mathrm{CO}_{2}$ by terrestrial ecosystems, and the absorption and emission of $\mathrm{CO}_{2}$ by the oceans Our model incorporates arguably the most detailed treatment of carbon-isotopes found in a global carbon-cycle model This is particularly important because carbon-isotope data, generated by LLNL's Center for Accelerator Mass Spectrometry facility and at other sites, typically provides the critical tests needed to build confidence in our model's predictive capability Our simulations of 
changes in carbon storage over the past two centuries using this model (Figure 1) are consistent with our understanding of the history of deforestation, and with observed changes in oceanic carbon-isotope ratios.

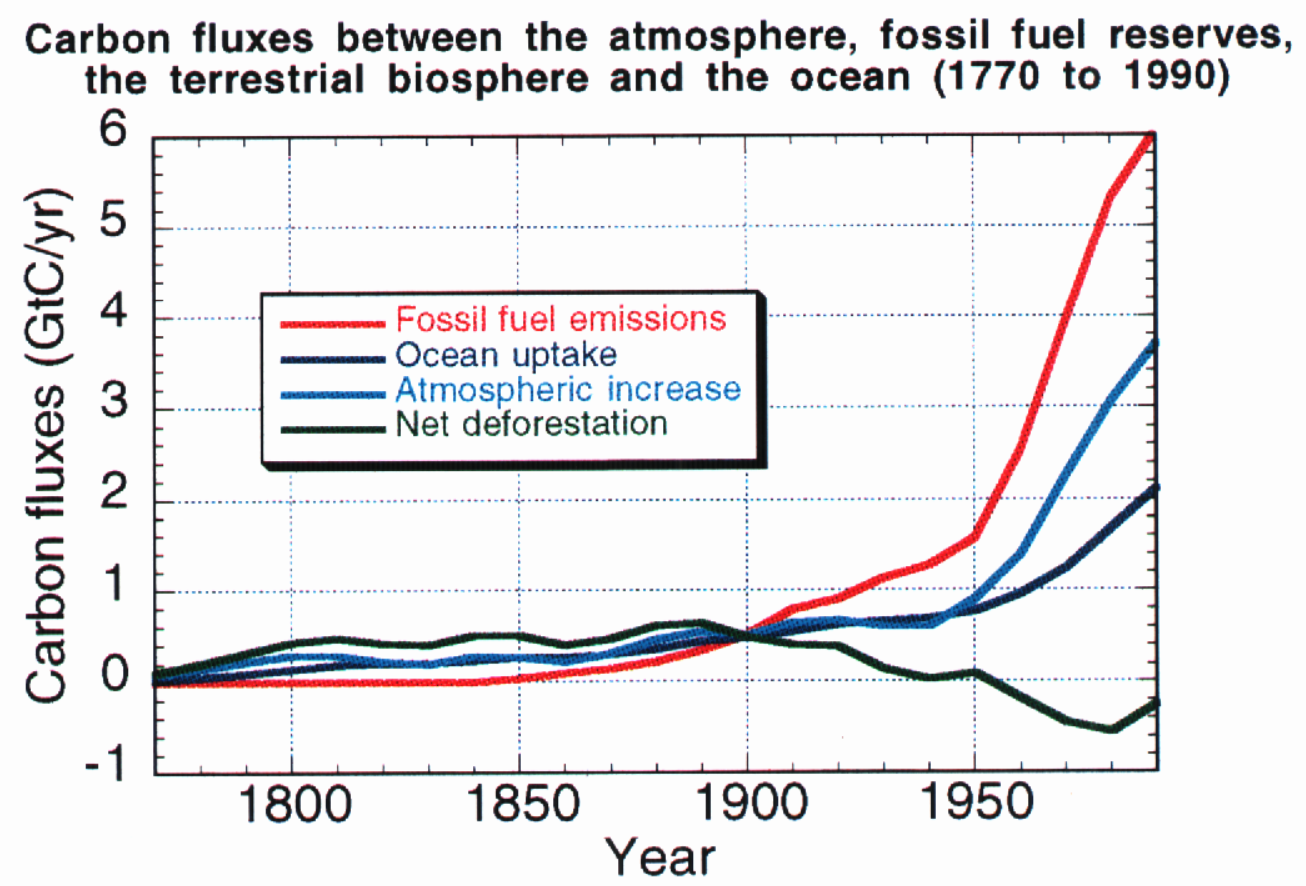

Figure 1. Simulated historical carbon fluxes using the LLNL model developed under this LDRD Strategic Initiative.

\section{Ocean Carbon-Cycle Modeling}

The oceanic portion of our carbon cycle model incorporates models of ocean circulation, chemistry, isotopic processes, and biology. We use a state-of-the-art ocean general circulation model with a dynamic/thermodynamic sea-ice model, running on massively parallel computers. Our model incorporates all leading physics enhancements into our model, including our own improvements to ocean model physics. The ocean circulation model is used to transport dissolved carbon dioxide, and other chemicals that impact the carbon cycle, through the simulated seas. Biological and chemical processes also impact the distribution of carbon dioxide in the oceans. We have developed our own 
ocean biogeochemistry and isotope fractionation models, incorporating the most recent research results This model is distinguished by its detailed treatment of isotopic processes, and, to our knowledge, is the first completed ocean biogeochemistry model implemented in a Bryan-Cox-derived ocean general circulation model We have used this model to simulate oceanic absorption of carbon for the past few centuries Our ocean modeling work has been highly regarded, and we have published influential papers on several topics including the global distributions of natural and bomb-produced radiocarbon (See Appendix)

\section{Land Carbon-Cycle Modeling}

The terrestrial ecosystem portion of our carbon cycle model is based on a detailed model of terrestrial ecosystem functioning This model, which has been widely published, is based on detailed simulation of biochemical processes that occur during photosynthesis It has successfully simulated carbon fluxes at specific sites at which detailed measurements have been made, and as a consequence is probably the most highly regarded model of carbon fluxes for application to forested ecosystems The fact that this model is physically based, and has been well-tested at a number of specific sites lends confidence to its application on a global scale Indeed, when $\mathrm{CO}_{2}$ fluxes from an early version of our land-surface model were transported through the atmosphere with an atmospheric transport model (see below), the observed seasonal and latidudinal distribution of $\mathrm{CO}_{2}$ in the atmosphere were well simulated

We developed and tested several terrestrial carbon cycle models, included a gridded (latitude-longitude) model, and a model based on broad geographical regions and biome times This latter model is based on nine geographical regions, corresponding in part to continents, it aggregates Earth's land area into 17 biomes for simulating land biomass production The model begins in the year $501 \mathrm{~B} \mathrm{C}$ and is incremented year-byyear to present Input in each cycle includes annual atmospheric $\mathrm{CO}_{2}$ concentration, rates of land-use change (e g, conversion of deciduous for est to cropland), rates of both natural and human-caused biome burning, rates of fuel wood burning, 1ates of logging for 
paper and other wood products, and rates of land clearing for shifting cultivation (i e , slash and burn agriculture) STB simulates annual net primary production (i e, the balance of plant photosynthesis and plant respiration) in each biome, based in part on atmospheric $\mathrm{CO}_{2}$ level Simulation of plant growth by increasing atmospheric $\mathrm{CO}_{2}$ is positively related to growing season temperature, based on a biochemical model of photosynthesis Net primary production is partitioned among plant leaves, roots, and stems, all of which have biome-specific longevities Dead plant parts are allocated, with biome-specific coefficients, among three soil carbon pools with differing rates of turnover It is noteworthy that charcoal is a product of fire in the model ( $\mathrm{CO}_{2}$ is another) because charcoal formation results in long-term storage of carbon on land

\section{Global Car bon-Cy'cleModeling}

We have performed important simulations of atmospheric transport of carbon, and have verified our calculations by comparing them with observations We used our land carbon cycle model, and our modeled air-sea carbon fluxes, to provide fluxes to one of our atmospheric transport models These models simulate the observed seasonal cycle quite well, and indicate the predictive capability of our models on seasonal-time scales 

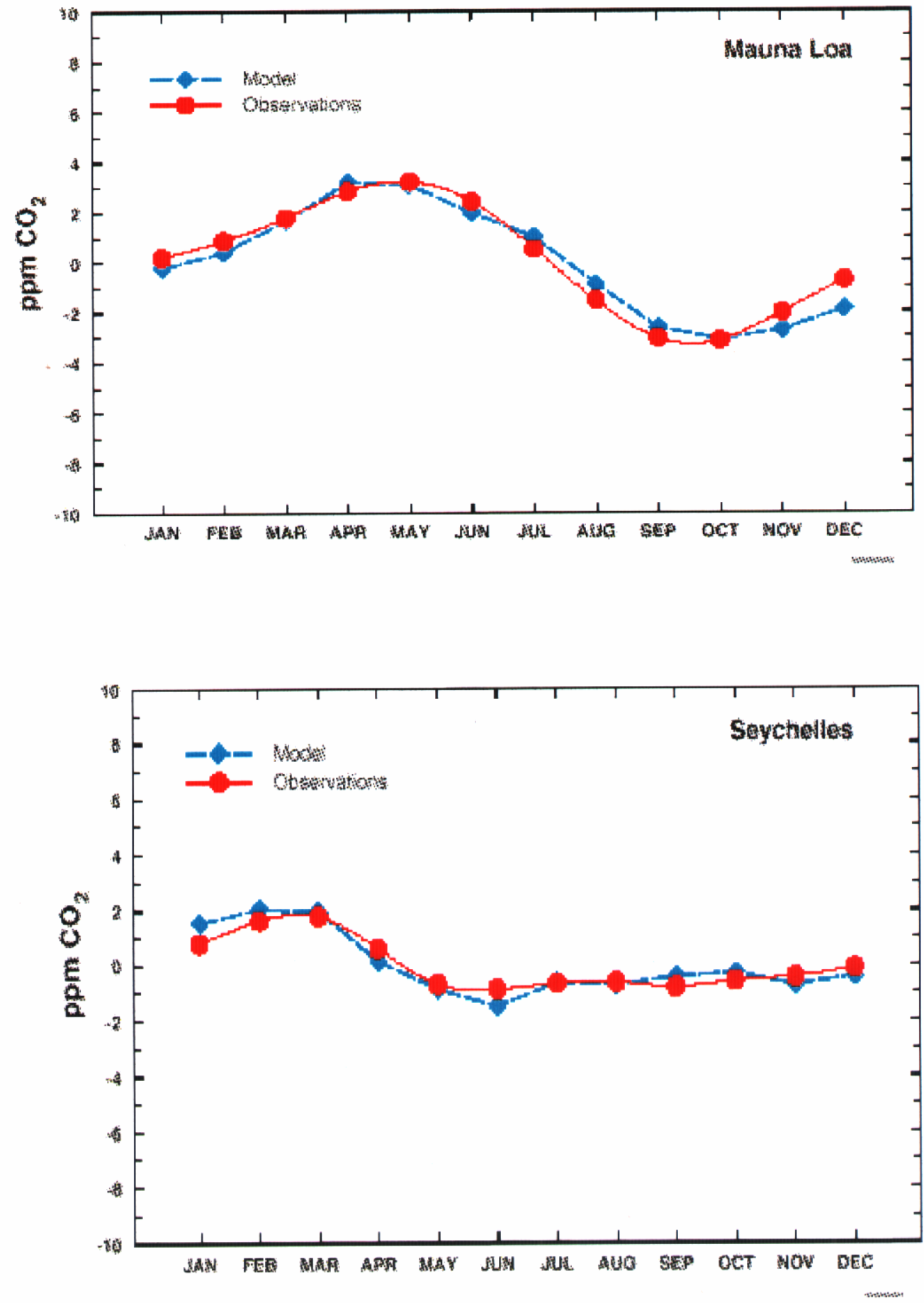

Figure 2. Model results and observations of atmospheric $\mathrm{CO} 2$ concentrations at two sites. These two sites, one in the Northern Hemisphere and one in the Southern, are both well simulated by our model. 
Another area in which we have made a significant contribution is in the understanding of the fate of radiocarbon produced in atmospheric nuclear weapons tests. Several papers in the literature suggested that the fate of this radiocarbon was poorly understood, and that carbon cycle models were poorly able to simulate the fate of this radiocarbon. We ran our stratospheric model, and our terrestrial and ocean carbon-cycle models with observed tropospheric boundary conditions. When previous researchers attempted this exercise, they found that the modeled inventory of radiocarbon in Earth's radiocarbon reservoirs differed significantly from the inferred cumulative bomb radiocarbon production. When we performed this exercise, our results conformed quite well with the inferred cumulative bomb radiocarbon production, giving us greater confidence in our model's predictive capability.

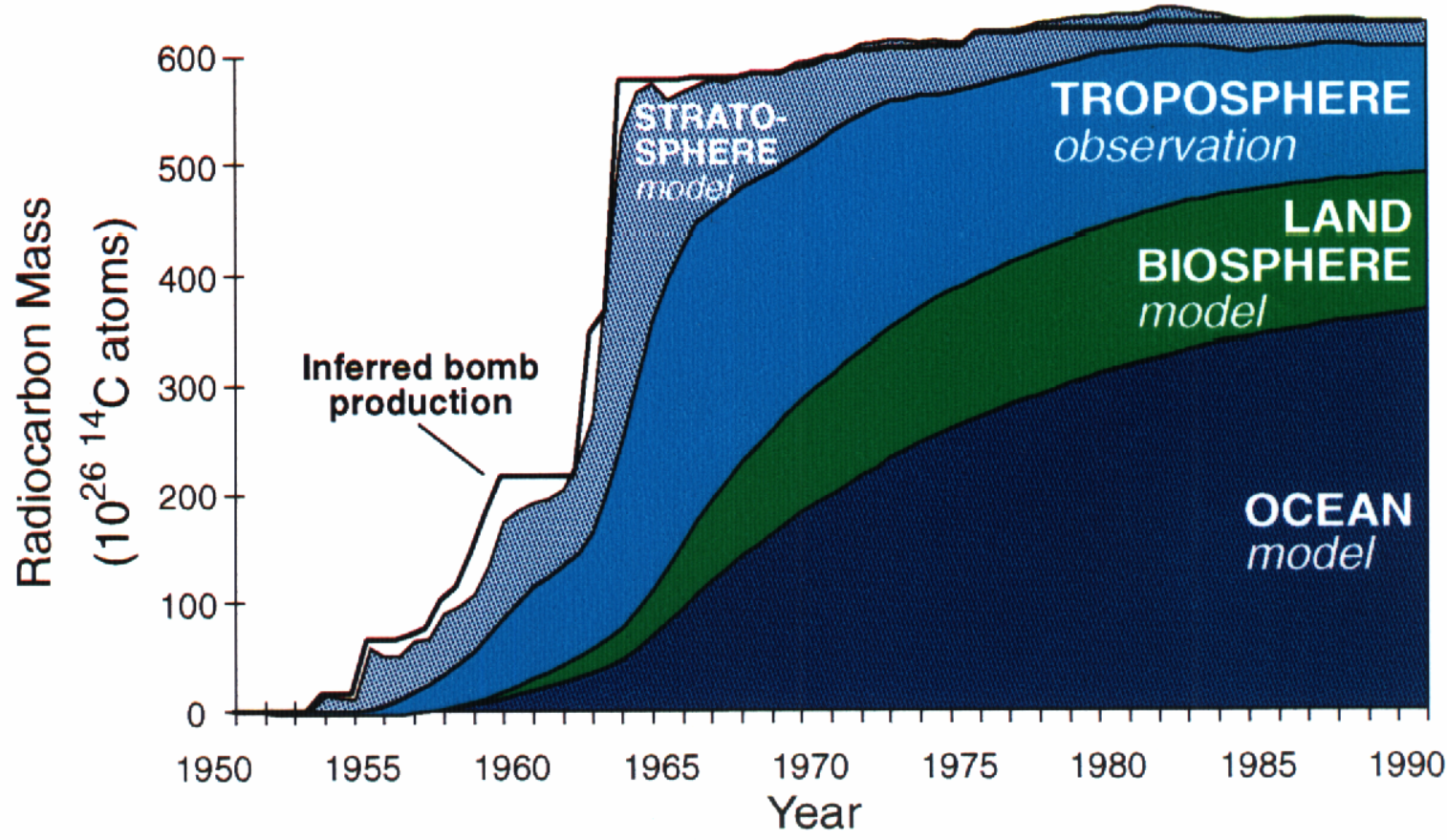

Figure 3. Simulated bomb radiocarbon mass in Earth's radiocarbon reservoirs, compared with the inferred cumulative bomb radiocarbon production.

\section{Carbon Isotope Data}

In the light of the importance of carbon-isotopic data for evaluating carbon-cycle models, we have developed what may be the world's most comprehensive database of radiocarbon data for the surface ocean. This database incorporates both data generated 
here at LLNL's Center for Accellerator Mass Spectrometry and data developed elsewhere. This database includes pre-bomb 14C data developed from corals or mollusc shells, and data from water samples.

\section{Pacific Surface Pre-Bomb $\Delta \mathbf{1 4} C$}

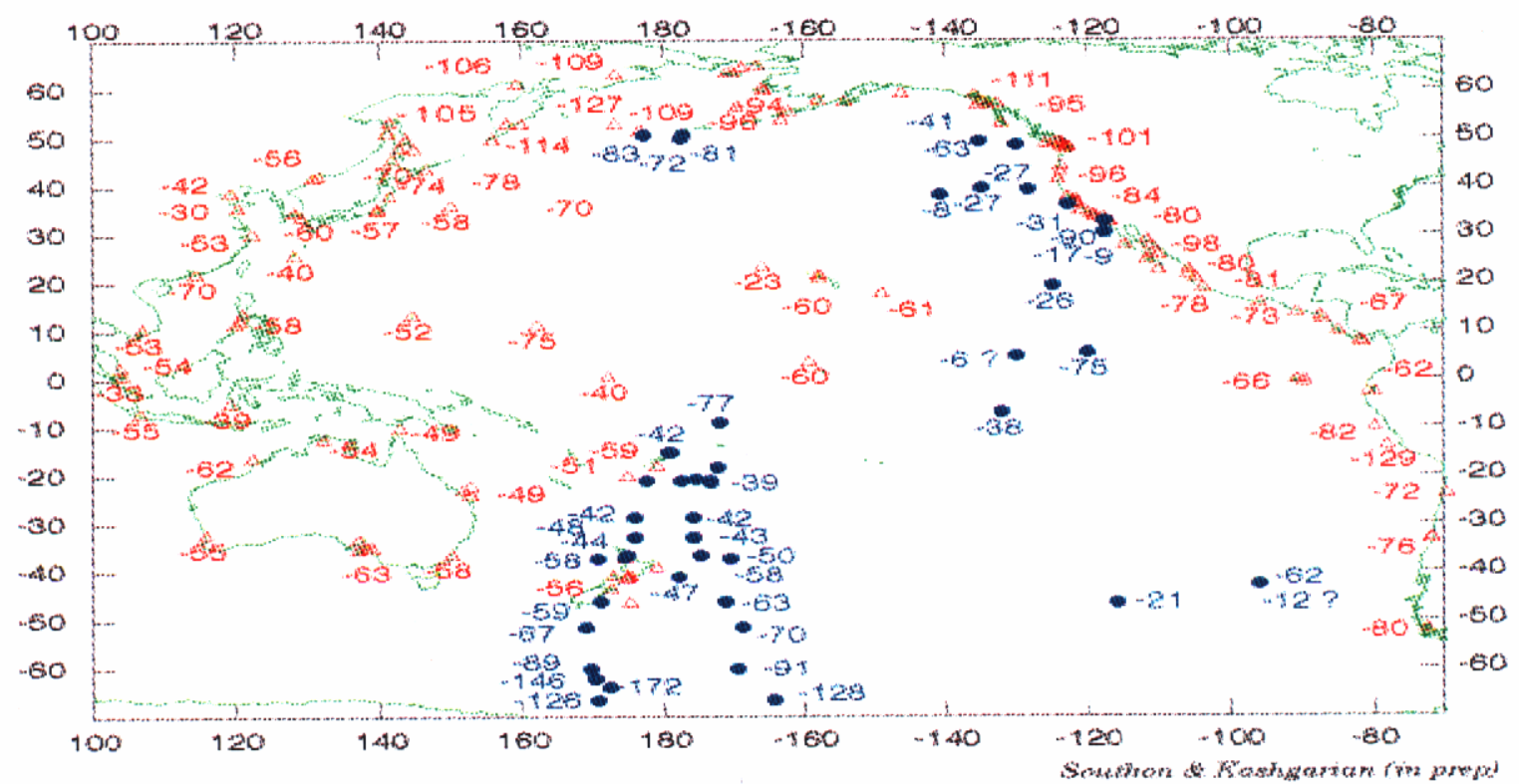

Figure 4. Example of data from LLNL's radiocarbon database.

Comparisons of model results with data indicate that the ocean model performs generally quite well, as shown by Figure 5 . Such comparisons are facilitated by threedimensional models because if an observation is made at a particular location on a particular date, the model result for that location and date can be directly compared with the observation. 

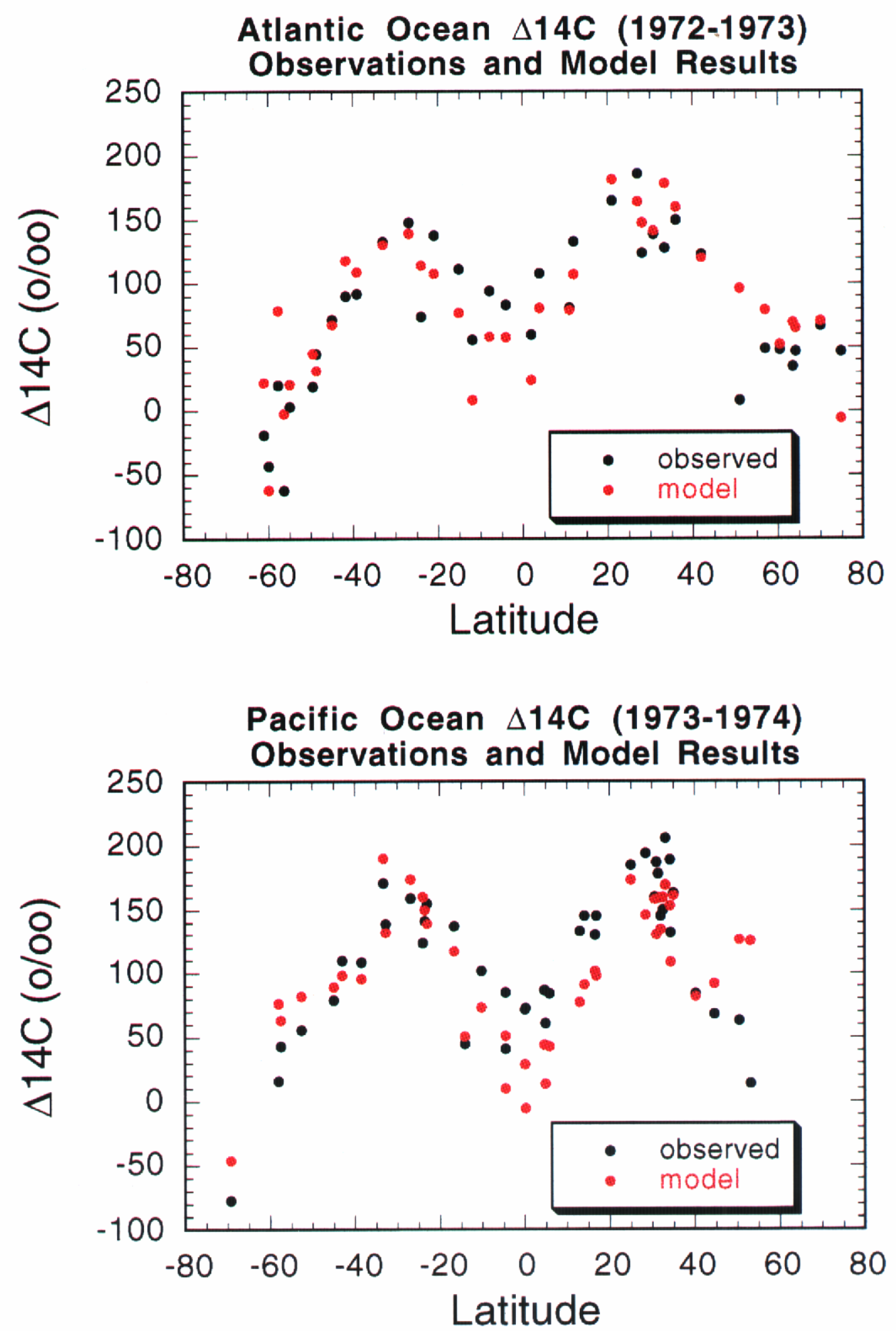

Figure 5. Comparison of ocean carbon-cycle model results with observations. 
Lawrence Livermore has developed one the most advanced and well-tested model of the global carbon cycle in the world We have done this, in part, because it is critical that the US Department of Energy have a group that understands the global carbon cycle and its uncertainties, and who have the capability to predict the consequences to the carbon cycle of various enetgy policy alternatives 